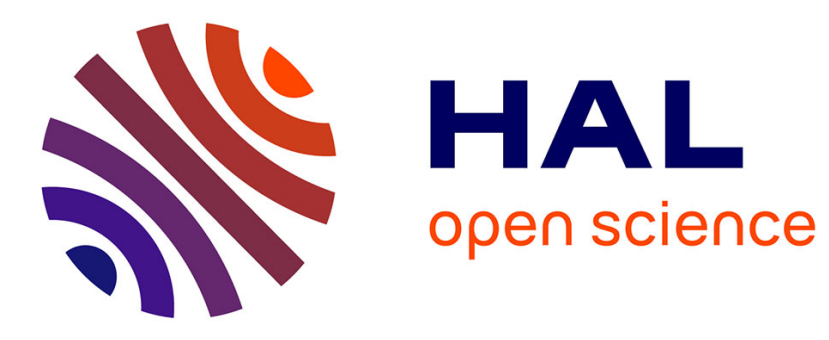

\title{
Electrochemical Characterisations of Ultra Thin Overoxidized Polypyrrole Films Obtained by One-Step Electrosynthesis
}

Ahmed Fakhry, Hubert Cachet, Catherine Debiemme-Chouvy

\section{To cite this version:}

Ahmed Fakhry, Hubert Cachet, Catherine Debiemme-Chouvy. Electrochemical Characterisations of Ultra Thin Overoxidized Polypyrrole Films Obtained by One-Step Electrosynthesis. Journal of The Electrochemical Society, 2013, 160 (10), pp.D465-D470. 10.1149/2.070310jes . hal-00858798

\section{HAL Id: hal-00858798 \\ https: / hal.sorbonne-universite.fr/hal-00858798}

Submitted on 27 Mar 2015

HAL is a multi-disciplinary open access archive for the deposit and dissemination of scientific research documents, whether they are published or not. The documents may come from teaching and research institutions in France or abroad, or from public or private research centers.
L'archive ouverte pluridisciplinaire HAL, est destinée au dépôt et à la diffusion de documents scientifiques de niveau recherche, publiés ou non, émanant des établissements d'enseignement et de recherche français ou étrangers, des laboratoires publics ou privés. 


\title{
Electrochemical Characterisations of Ultra Thin Overoxidized Polypyrrole Films Obtained by One-step Electrosynthesis.
}

\author{
A. Fakhry ${ }^{1,2}$, H. Cachet ${ }^{1,2}$, C. Debiemme-Chouvy ${ }^{1,2, ~ *}$ \\ ${ }^{1}$ CNRS, Laboratoire Interfaces et Systèmes Electrochimiques, UPR 15, 75005 Paris, France \\ ${ }^{2}$ UPMC, Univ Paris 06, LISE, 4 place Jussieu, CC 133, 75005 Paris, France
}

\begin{abstract}
Ultra thin (10-20 nm) and pin-hole free overoxidized polypyrrole films were directly electrosynthezised under potentiostatic conditions in the presence of weak-acid anions, specifically monohydrogenophosphate. Various overoxidized polypyrrole membranes were fabricated in these conditions at different potentials in the range of 0.70 to $0.90 \mathrm{~V} / \mathrm{SCE}$. Their non-conductive property and blocking character towards anions were verified by cyclic voltammetry and electrochemical impedance spectroscopy in the presence of the ferricyanide/ferrocyanide redox couple. The results show that these films are definitively ultra thin pine-hole free and non-conductive membrane. For comparison purposes, classical polypyrrole films were also prepared in the presence of perchlorate ions, overoxidized in $\mathrm{KOH}$ solution, and finally electrochemically characterized.
\end{abstract}

Keywords: overoxidized polypyrrole, EIS, one-step electrochemical synthesis, anion rejection.

* Corresponding author. Email : catherine.debiemme-chouvy@ upmc.fr ; Phone : +33 144274149. 


\section{INTRODUCTION}

Polypyrrole (PPy) is one of the most widely investigated conducting organic polymer notably due to its high conductivity under its doped oxidized form. However, some analytical applications concern overoxidized polypyrrole (OPPy) films.[1,2] The main characteristics of overoxidized polypyrrole are the following: (i) the polymer is de-doped i.e. the anions which dope the polymer under its oxidized conducting form are expelled from the polymer, (ii) some carbonyl groups are present in $\beta$-position of some pyrrole rings, therefore the conjugation is disrupted and the polymer film is no more conductive.[1,3,4,5,6] It has been shown that these OPPy films could be used as a rejection membrane or as a permselective coating against anions.[3,4,7,8,9,10,11] Actually, they are as effective as Nafion membrane for the rejection of the anions.[12,13,14]

Generally the fabrication of overoxidized polypyrrole membrane is performed in two steps, the first one being the electrogeneration of a PPy film and the second one is the overoxidation of the film in an indifferent electrolyte, often sodium hydroxide.[6,8,15,16,17,18] The overoxidation of a conductive PPy film (doped film) can take place when it is anodically polarized in an indifferent aqueous electrolyte i.e. when water oxidation occurs leading to the generation of hydroxyl radicals.[19] Sometimes this second step can last several hours, until the anodic current is very low and constant. Recently, Debiemme-Chouvy has shown that the presence of solely anions of a weak acid (weak-acid anions) in the pyrrole solution, such as monohydrogenophosphate or carbonate, allows one to rapidly and directly deposit an ultra thin film of OPPy on the metal electrode.[20] This kind of films could be obtained under potentiodynamic or potentiostatic conditions. Actually, this process has been explained considering the proton release during the pyrrole oxidation:

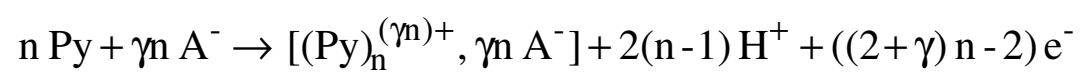


$\gamma$ stands for the doping level of the polymer. Note that this equation shows that the presence of anions $\left(\mathrm{A}^{-}\right)$in the pyrrole (Py) solution is essential for polymer generation.

In the presence of weak-acid anions, the released protons are captured by these anions implying two phenomena: a limitation of the decrease of the interfacial $\mathrm{pH}$ and a huge decrease of the interfacial concentration of anions. Thus, since none or only a few anions are present at the electrode/solution interface, reaction (1) cannot take place and as the interfacial $\mathrm{pH}$ is high water oxidation can occur $\left(\mathrm{E}=1.0-0.06 \mathrm{pH}(\mathrm{V} v s . \mathrm{SCE})\right.$, at $\left.25^{\circ} \mathrm{C}\right)$. Water oxidation leads to the production of hydroxyl radicals which overoxidize the PPy film formed at the very beginning of the electrochemical process.

$$
\left[(\mathrm{Py})_{n}^{(\gamma n)+}, \gamma \mathrm{A} \mathrm{A}^{-}\right]+\mathrm{xOH}^{\bullet} \rightarrow \mathrm{OPPy}+\gamma \mathrm{A} \mathrm{A}^{-}+\ldots
$$

In the present work, the electrical characteristics of OPPy films synthesized in the presence of only monohydrogenophosphate $\left(\mathrm{HPO}_{4}{ }^{2-}\right)$ as anions are described. They have been determined by cyclic voltammetry (CV) and by electrochemical impedance spectroscopy (EIS) in the presence of a monoelectronic rapid redox couple $\left(\mathrm{Fe}(\mathrm{CN})_{6}^{3-/ 4-}\right)$. Moreover, 'classical' PPy films were also electrogenerated and then overoxidized in $\mathrm{KOH}$ solution. The performances of very thin OPPy films formed by a one step process (using weak-acid anions) are compared with those of a film formed by a classical two-step process.

\section{EXPERIMENTAL}

The polypyrrole films were synthesized using pyrrole solution preliminarily distilled.[21] All of the solutions were prepared with bi-distilled water. Py solution, $\mathrm{K}_{2} \mathrm{HPO}_{4}, \mathrm{LiClO}_{4}$, $\mathrm{K}_{3} \mathrm{Fe}(\mathrm{CN})_{6}, \mathrm{~K}_{4} \mathrm{Fe}(\mathrm{CN})_{6}, \mathrm{KOH}$ and $\mathrm{KCl}$ salts were purchased from Aldrich.

The electrochemical experiments were performed in a classical three-electrode electrochemical cell. A platinum foil was used as counter electrode and a saturated calomel electrode (SCE) as the reference electrode. A double junction was used in order to avoid 
chloride diffusion into the Py solution. The working electrode was a Pt electrode $(S=0.071$ $\mathrm{cm}^{2}$ ) for electrochemical studies and Au/mica or a-CNx [22,23] substrates for SEM observations. The cyclic voltammetry and electrochemical impedance spectroscopy experiments were performed using an Autolab PGSTAT30 (Ecochemie) potentiostat/galvanostat controlled with the GPES or FRA softwares. The EIS experiments were performed at the formal potential of the redox system, from $10 \mathrm{mHz}$ to $10 \mathrm{kHz}$ (9 points per decade) and a $10 \mathrm{mV}$ (r.m.s.) ac perturbation for a $0.01 \mathrm{~mol} \mathrm{~L}^{-1} \mathrm{~K}_{4} \mathrm{Fe}(\mathrm{CN})_{6} / \mathrm{K}_{3} \mathrm{Fe}(\mathrm{CN})_{6}$ in $0.5 \mathrm{~mol} \mathrm{~L}{ }^{-1} \mathrm{KCl}$ solution.

EIS spectrum simulations were done on the basis of electrical equivalent circuits. All the elements contained in a given equivalent circuit were determined by fitting its frequency dependence to the experimental impedance with a home-made simplex program using Nelder and Mead down-hill strategy.[24]

The scanning electron microscopy (SEM) images were obtained from a SEM-field-emission gun (FEG) microscope, Ultra 55 Zeiss operating at $3 \mathrm{kV}$.

\section{RESULTS AND DISCUSSION}

1. One-step electrosynthesis of OPPy film

The OPPy films were prepared from a pyrrole aqueous solution containing only monohydrogenophosphate species as anions. The $\mathrm{pH}$ of this solution was 8.6. The film synthesis was performed under potentiostatic conditions and various potentials were tested. From Figure 1A, it is clear that whatever the applied potential (from 0.70 to $0.90 \mathrm{~V} / \mathrm{SCE}$ ) the shape of the chronoamperometric curves is the same. First, the anodic current is high, between 

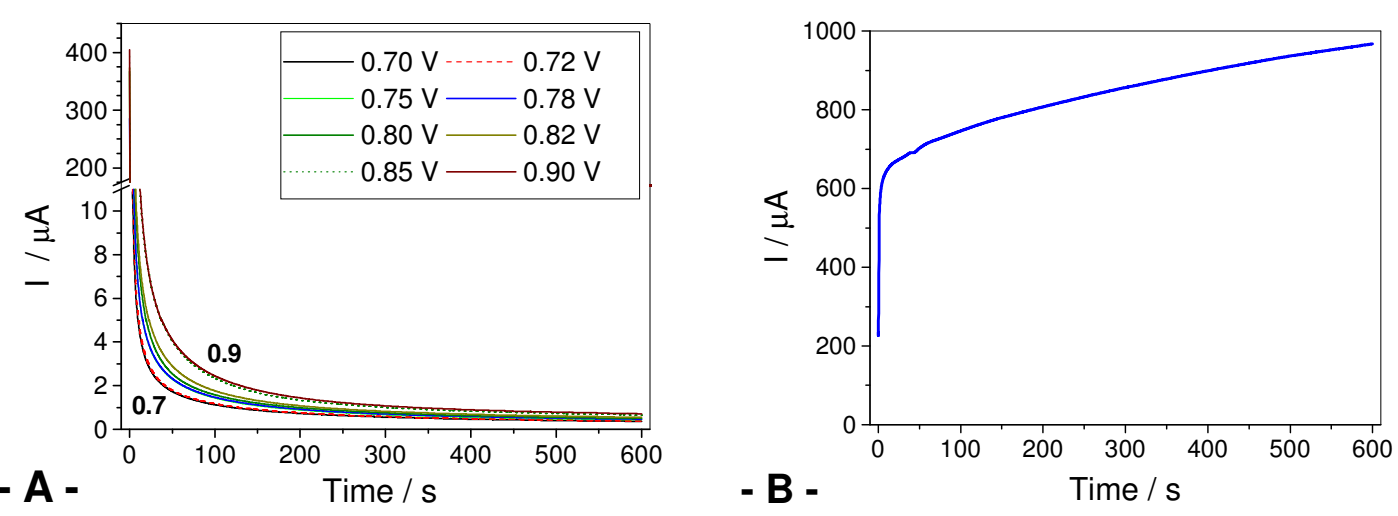

Figure 1: Polymeric membrane electrosynthesis. A) Current vs. time at a Pt electrode $(S=$ $\left.0.071 \mathrm{~cm}^{2}\right)$ polarized at different potentials, from 0.70 to $0.90 \mathrm{~V} / \mathrm{SCE}$. B) at $0.70 \mathrm{~V} / \mathrm{SCE}(\mathrm{Q}=505$ $m C$ ). Electrolyte: aqueous solution containing $0.15 \mathrm{M} \mathrm{Py}+0.2 \mathrm{M} \mathrm{K}_{2} \mathrm{HPO}_{4}(\mathrm{~A})$ or $0.2 \mathrm{M} \mathrm{LiClO}_{4}$ (B).

160 and $400 \mu \mathrm{A}$ (see Table 1), then it decreases very rapidly until a very low value, between 0.4 and $0.7 \mu$ A. For each potential tested, the initial $\left(\mathrm{I}_{0}\right)$ and final $\left(\mathrm{I}_{\mathrm{f}}\right)$ currents are reported in Table 1 as well as the anodic charge that passed through the electrode for 600 seconds, which is the duration of the film synthesis. The ratio between $I_{f}$ and $I_{0}$ is in the range of 0.0014 to 0.0023. All these results indicate that the Py oxidation rate is not constant and rapidly decreases with time. 
Table 1: One-step electrosynthesis of OPPy films. Applied potentials, initial and final currents and anodic charges passed through the Pt electrode polarized for 600 s in 0.15 M Py $+0.2 \mathrm{M} \mathrm{K}_{2} \mathrm{HPO}_{4}$ solution.

\begin{tabular}{|c|c|c|c|c|}
\hline $\mathrm{E}(\mathrm{V} / \mathrm{SCE})$ & $\mathrm{I}_{0}(\mu \mathrm{A})$ & $\mathrm{I}_{\mathrm{f}}(\mu \mathrm{A})$ & $\mathrm{Q}_{\text {anodic }}(\mathrm{mC})$ & $\mathrm{I}_{\mathrm{f}} / \mathrm{I}_{0}$ \\
\hline 0.70 & 161 & 0.364 & 0.63 & 0.0023 \\
\hline 0.72 & 201 & 0.383 & 0.66 & 0.0019 \\
\hline 0.75 & 271 & 0.436 & 0.80 & 0.0016 \\
\hline 0.78 & 285 & 0.463 & 0.83 & 0.0016 \\
\hline 0.80 & 367 & 0.499 & 0.85 & 0.0014 \\
\hline 0.82 & 373 & 0.548 & 0.99 & 0.0015 \\
\hline 0.85 & 394 & 0.653 & 1.26 & 0.0016 \\
\hline 0.90 & 405 & 0.715 & 1.34 & 0.0018 \\
\hline
\end{tabular}

For a diffusion limited process, the Cotterell equation is $\mathrm{I}=\mathrm{kt}^{-1 / 2}$ where I stands for the current, $\mathrm{k}$ the kinetic constant and $\mathrm{t}$ the time. Thus, if $\mathrm{I}_{0}$ is determined at $\mathrm{t}=0.1 \mathrm{~s}$ and $\mathrm{I}_{\mathrm{f}}$ after $600 \mathrm{~s}$ of polarization, then $I_{f} / I_{0}=(0.1 / 600)^{1 / 2}=0.013$. This value is about ten times higher than the values determined in our experimental conditions (see Table 1). Therefore the pyrrole polymerization process is not limited by the diffusion, actually it is progressively blocked due to the overoxidation of the polymer already deposited on the electrode. This finding was confirmed by the fact that the relationship between $I$ and $\mathrm{t}^{-1 / 2}$ is not linear.

Besides, it has been observed that for all the potentials tested, the films electrogenerated on the Pt electrode were not visible to the naked eye the electrode surface appeared yellow. These results are in good agreement with the very low anodic charges passed through the electrode during its polarization (see Table 1), about five hundred times lower than the anodic charge in the presence of perchlorate (see Figure 1B). 
To confirm this finding another test was performed. After 600 seconds of polarization at 0.70 V/SCE, the addition of $\mathrm{LiClO}_{4}$ in the $\mathrm{Py}+\mathrm{K}_{2} \mathrm{HPO}_{4}$ solution was done and the applied potential was increased up to $0.78 \mathrm{~V} / \mathrm{SCE}$. Under these conditions no film growth was detected. The initial film electrogenerated at $0.70 \mathrm{~V} / \mathrm{SCE}$ is definitively a non conductive membrane i.e. an overoxidized PPy film.

SEM images of OPPy films electrogenerated at $0.75 \mathrm{~V} / \mathrm{SCE}$ and $0.90 \mathrm{~V} / \mathrm{SCE}$ on an a-CNx substrate are shown in Figure 2. The film thicknesses are very low between 10 and $20 \mathrm{~nm}$.
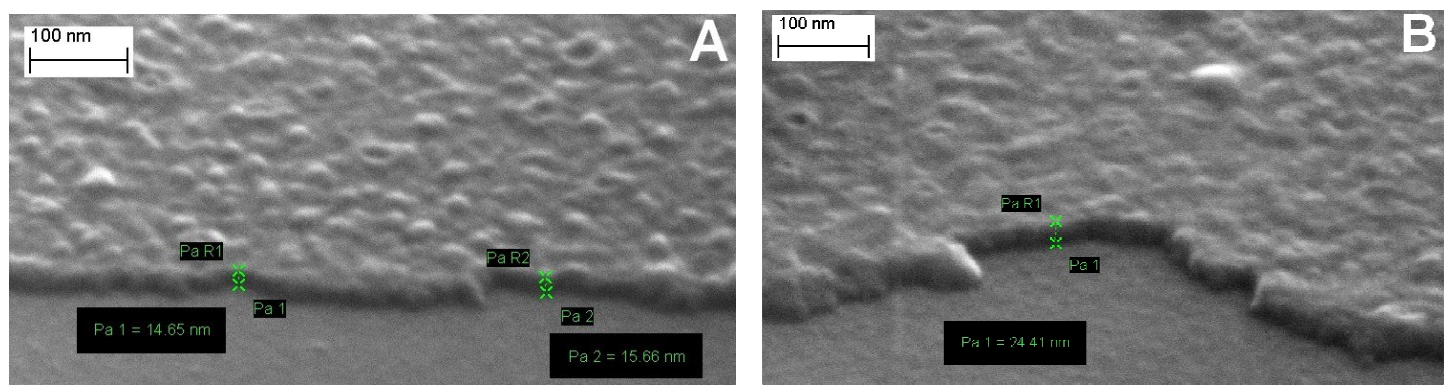

Figure 2: OPPy membranes. SEM images of the cross section $\left(\theta=65^{\circ}\right)$ of polymers electrogenerated on a-CNx substrate for 600 seconds at $0.75 \mathrm{~V} / \mathrm{SCE}(\boldsymbol{A})$ and $0.90 \mathrm{~V} / \mathrm{SCE}(\boldsymbol{B})$, in $0.15 \mathrm{MPy}+0.20 \mathrm{M} \mathrm{K}_{2} \mathrm{HPO}_{4}$ aqueous solution. The film thicknesses, measured between the crosses, are $14.6 \mathrm{~nm}(A), 15.7 \mathrm{~nm}(A)$ and $24.4 \mathrm{~nm}(B)$.

2. Electrochemical characterizations of the OPPy films

\subsection{CVs in the presence of redox species}

First of all, to confirm that the films are non conductive and reject the anions, some experiments were conducted in the presence of the monoelectronic redox couple $\mathrm{Fe}(\mathrm{CN})_{6}^{3-/ 4}$ in $\mathrm{KCl}$ solution. From Fig. 3A, it is clear that for all the electrodes coated with an OPPy film, 

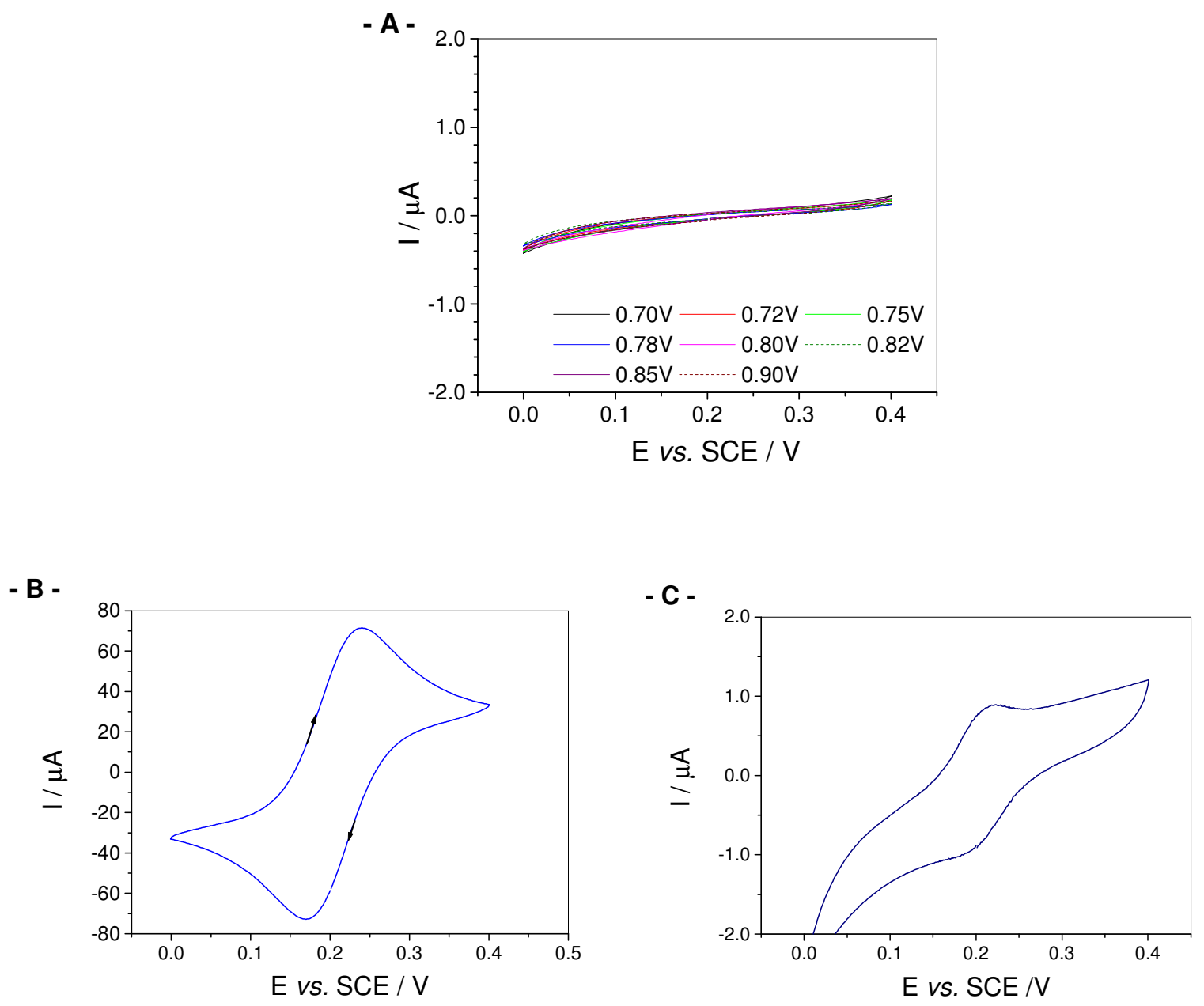

Figure 3: CV responses of (O)PPy-coated electrodes. Current vs. potential curves recorded at a Pt disk electrode coated with (A) an OPPy film electrogenerated at different potentials indicated in the graph, (B) a $\mathrm{ClO}_{4}^{-}$doped PPy film $(5 \mathrm{mC}) .(\mathrm{C}) \mathrm{CV}$ response of the $\mathrm{ClO}_{4}^{-}$ doped PPy film (B) after its overoxidation by polarization at 0.8 V/SCE for 20 minutes in 0.1M KOH. Electrolyte: $10 \mathrm{mM} \mathrm{Fe}\left(\mathrm{CN}_{6}{ }^{4-13-}+0.5 \mathrm{M} \mathrm{KCl}\right.$. Potential scan rate: $10 \mathrm{mV} \mathrm{s}{ }^{-1}$.

extremely tiny currents are detected. For comparison the response obtained for a classical film i.e. a film electrogenerated in the presence of $\mathrm{ClO}_{4}{ }^{-}$instead of $\mathrm{HPO}_{4}{ }^{2-}$ is shown in Figure 3B. In this case, the electrochemical response of the ferri-ferrocyanide redox system is detected in 
good agreement with the fact that the polymer is under its oxidized state (doped and conductive form).

\subsection{EIS in the presence of redox species}

In order to specify the results obtained by CV, EIS experiments were carried out. Figure 4 shows the Nyquist diagrams of OPPy-coated Pt electrodes, in contact with a $0.5 \mathrm{M} \mathrm{KCl}$ solution containing the redox couple $\mathrm{Fe}(\mathrm{CN})_{6}{ }^{4-/ 3-}$ recorded at the formal potential of +0.21 V/SCE. The Nyquist diagrams depicted in Figure 4 are mainly characterized by a very large capacitive loop appearing as a slightly asymmetric depressed semicircle. Such a distribution of time constants can be related to a distribution of either dielectric or conductive properties of the OPPy film along the

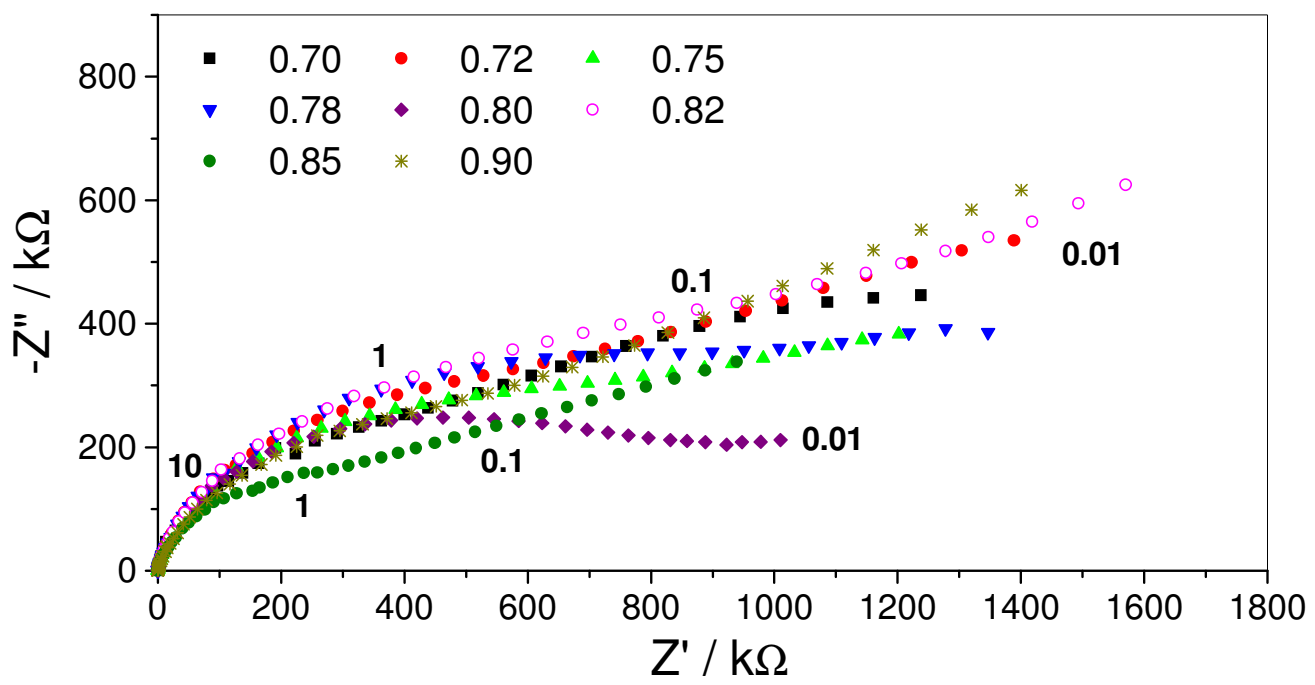

Figure 4: EIS response of OPPy-coated electrode. Nyquist EIS diagrams recorded at 0.21 V/SCE for OPPy-coated Pt electrodes in contact with a $10 \mathrm{mM} \mathrm{Fe}(\mathrm{CN})_{6}^{4-/ 3-}+0.5 \mathrm{M} \mathrm{KCl}$ solution. The OPPy films were synthesized at different potentials indicated in the graph. Some frequencies in $\mathrm{Hz}$ are indicated. 
dimension normal to the electrode surface. Taking into account the generation process of the OPPy films, a conductivity gradient can be expected between the Pt/OPPy and the OPPy/solution interfaces.

Such a situation has been formally addressed by Young in the case of blocking oxide layers, assuming that the conductivity $\sigma(\mathrm{x})$ within the films varies exponentially as $\sigma(\mathrm{x})=\sigma(0) \exp (-$ $\mathrm{x} / \delta$ ) where $\delta$ is a characteristic length, shorter than the film thickness d.[25,26,27] The relative dielectric constant $\varepsilon$ inside the film is assumed to be constant. Within these assumptions, the impedance $Z_{\text {Young }}$ can be expressed as:

$$
Z_{\text {Young }}=\frac{\delta / d}{j \omega C_{\mathrm{f}}} \cdot \ln \left(\frac{1+\mathrm{j} \omega \tau \exp (\mathrm{d} / \delta)}{1+\mathrm{j} \omega \tau}\right)
$$

where $C_{\mathrm{f}}=\varepsilon_{\mathrm{o}} \varepsilon \mathrm{S} / \mathrm{d}$ is the film dielectric capacity, $\mathrm{S}$ the geometric surface of the film and $\tau=$ $\varepsilon \varepsilon_{0} / \sigma(0)$ is a time constant characteristic of the film $\left(\varepsilon_{0}=8.8410^{-12} \mathrm{~F} / \mathrm{m}\right.$ in MKSA units $)$. The tiny faradaic current observed in the presence of the redox species (see Fig. 3A) is accounted for by adding in parallel to the Young impedance a transfer resistance $R_{t}$ in series with a diffusion impedance taken as a Nernst diffusion impedance:

$$
Z_{\text {Diff }}=R_{N} \frac{\operatorname{th} \sqrt{j \omega \tau_{d}}}{\sqrt{j \omega \tau_{d}}}
$$

Figure 5(1) shows the equivalent electrical circuit used to analyze the frequency dependence of the EIS diagrams obtained for the OPPy films. Seven parameters $\left(\delta / d, C_{f}, \tau, R_{t}, R_{N}, \tau_{d}\right.$ and $\mathrm{R}_{\mathrm{s}}$ ) are involved in the model. The fitted parameters of the spectra reported in Fig. 4 are summarized in Table 2. The reduced standard deviation calculated over the real and imaginary components assuming a $1 \%$ error on impedance modulus are also reported. 

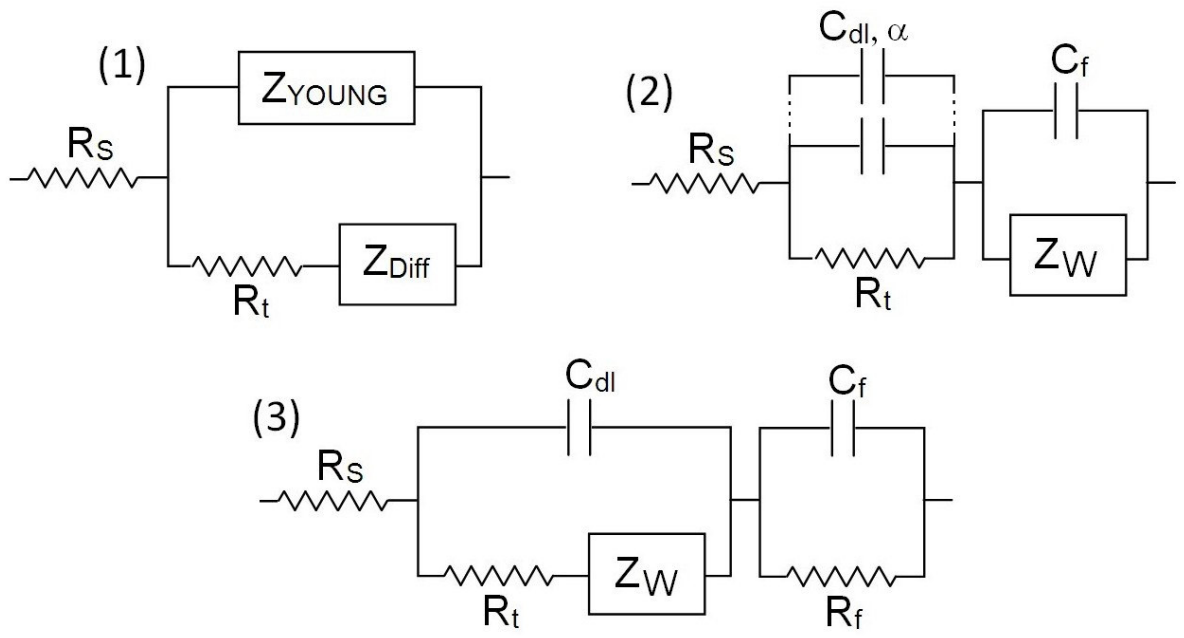

Figure 5: Equivalent electrical circuits. Electrical models used to fit the impedance response of the polypyrrole films synthesized at $0.70 \leq E \leq 0.85 \mathrm{~V} / E C S$. (1) one-step OPPy, (2) doped PPy (interfacial impedance represented by a Cole-Cole distribution as given in Table 3), (3) two-step OPPy.

The first information obtained from the data reported in Table 2 is the relative dielectric constant $\varepsilon$ of the polymeric film. This parameter was determined by using ten film thicknesses $\mathrm{d}$ measured for four different samples. Therefore, ten values of $\varepsilon$ were obtained assuming the film capacity $C_{f}$ to be described by that of a plane condenser with the surface $S=0.071 \mathrm{~cm}^{2}$, according to:

$$
\mathcal{E}=\frac{d \cdot C_{f}}{\varepsilon_{0} \cdot S}
$$

It reads a mean value of $\varepsilon=12 \pm 2$. This value seems reasonable for a non conducting polypyrrole material, but it is hardly comparable to literature data which are scarce. A value of 13.6 was found for chemically synthesized PPy films.[28,29] A number of investigations was performed to measure the dielectric permittivity $\varepsilon$ of PPy films at high frequencies in the $\mathrm{GHz}$ range.[30] At a frequency of $2.45 \mathrm{GHz}, \varepsilon$ was found around 10 for lightly doped PPy films. 
Table 2: EIS analyses. Fitted parameters of OPPy films directly synthesized at different potentials $E_{o x}$ according to the electrical model depicted in Fig. 5(1) (electrode surface: 0.071 $\left.\mathrm{cm}^{2}\right)$. The experimental spectra are shown in Fig. 4. Calculated parameters: $\sigma(0), \sigma_{s}, \theta$ (see text). 


\begin{tabular}{|c|c|c|c|c|c|c|c|c|}
\hline $\begin{array}{c}\mathrm{E}_{\mathrm{ox}} \\
(\mathrm{V} / \mathrm{SCE})\end{array}$ & 0.70 & 0.72 & 0.75 & 0.78 & 0.80 & 0.82 & 0.85 & 0.90 \\
\hline$\delta / \mathrm{d}$ & 0.1000 & 0.0965 & 0.1001 & 0.1000 & 0.1075 & 0.0959 & 0.0911 & 0.0936 \\
\hline $\begin{array}{c}\mathrm{C}_{\mathrm{f}} \\
(\mathrm{nF})\end{array}$ & 70.2 & 64.0 & 57.1 & 54.6 & 46.0 & 45.8 & 37.2 & 32.6 \\
\hline $\begin{array}{c}\tau \\
\left(10^{-6} \mathrm{~s}\right)\end{array}$ & 71.8 & 58.5 & 52.2 & 47.9 & 53.7 & 40.9 & 9.5 & 11.4 \\
\hline $\begin{array}{c}\mathrm{R}_{\mathrm{t}} \\
(\Omega)\end{array}$ & 458710 & 640320 & 630110 & 696090 & 662940 & 690940 & 389180 & 368520 \\
\hline $\begin{array}{c}\mathrm{R}_{\mathrm{N}} \\
(\mathrm{M} \Omega)\end{array}$ & 7.58 & 7.54 & 8.17 & 11.1 & 66.2 & 10.4 & 67.2 & 258 \\
\hline $\begin{array}{c}\tau_{\mathrm{d}} \\
(\mathrm{s})\end{array}$ & 161 & 143 & 145 & 128 & 10870 & 146 & 5530 & 37000 \\
\hline $\begin{array}{c}\mathrm{R}_{\mathrm{s}} \\
(\Omega)\end{array}$ & 42.7 & 42.6 & 45.3 & 43.3 & 58.3 & 44.8 & 34.0 & 33.9 \\
\hline $\begin{array}{c}\text { Standard } \\
\mathrm{deviation}\end{array}$ & 1.6398 & 1.7232 & 1.6833 & 2.1829 & 1.5029 & 2.0158 & 1.5931 & 2.6213 \\
\hline $\begin{array}{c}\sigma(0) \\
\left(\mu \mathrm{S} \mathrm{cm}{ }^{-1}\right)\end{array}$ & 0.010 & 0.012 & 0.014 & 0.015 & 0.013 & 0.018 & 0.076 & 0.063 \\
\hline $\begin{array}{c}\sigma_{\mathrm{s}} \\
\left(10^{-12} \mathrm{~S} \mathrm{~cm}{ }^{-1}\right)\end{array}$ & 0.46 & 0.39 & 0.63 & 0.68 & 1.225 & 0.52 & 1.30 & 1.45 \\
\hline \begin{tabular}{c}
$\theta(\%)$ \\
\hline
\end{tabular} & 0.00081 & 0.00058 & 0.00059 & 0.00053 & 0.00056 & 0.00054 & 0.00095 & 0.0010 \\
\hline
\end{tabular}

Accordingly the largest film conductivity $\sigma(0)$ at the OPPy/solution interface is given by:

$$
\sigma(0)=\frac{\varepsilon \varepsilon_{0}}{\tau}
$$

The calculated values for each applied potential tested are given in Table 2. From these data, it is clear that the electrical isolating character of the OPPy film is the best when the applied 
potential $\left(\mathrm{E}_{\mathrm{ox}}\right)$ lies in the range of $0.70 \leq \mathrm{E}_{\mathrm{ox}} \leq 0.82 \mathrm{~V} / \mathrm{SCE}$ (see Fig. 6). The conductivity gradient mainly applies to about a tenth of the film thickness, regarding the $\delta / d$ values closed to 0.1 . According to Young model, the film conductivity $\sigma_{\mathrm{s}}$ at the Pt/OPPy interface can be calculated as:

$$
\sigma_{s}=\sigma(0) \cdot \exp \left(-\frac{d}{\delta}\right)
$$

The attenuation factor $(\exp (-\mathrm{d} / \delta))$ is of the order of $10^{4}-10^{8}$ yielding the $\sigma_{\mathrm{s}}$ values in the range $10^{-12} \mathrm{~S} / \mathrm{cm}$ (Table 2) whatever the potential used for the film synthesis with an optimum value of $0.3910^{-12} \mathrm{~S} / \mathrm{cm}$ for $\mathrm{E}_{\mathrm{ox}}=0.72 \mathrm{~V} / \mathrm{SCE}$. These findings validate the synthesis route tested herein to produce in one step a highly blocking ultra thin polymeric film. In the presence of redox species, a residual current can be observed involving a very small fraction $\theta$ of the electrode surface. This fraction can be evaluated by comparing the EIS response of a very thin PPy conductive (doped) film generated with an anodic charge of $5 \mathrm{mC}$, investigated in the same electrochemical conditions (see Fig. 7). The frequency dependence of the impedance is well accounted for by a Randles circuit involving a Warburg diffusion impedance in series with the transfer resistance.

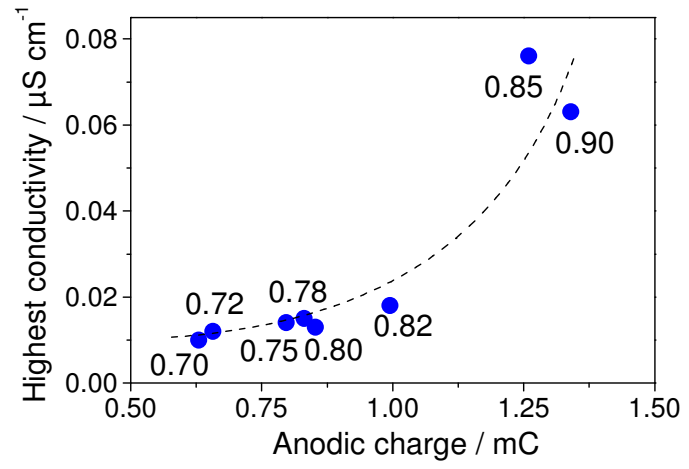

Figure 6: Conductivity of OPPy films. Variation of the highest conductivity ( $(0))$ of the OPPy films as a function of the electrical charge passed during their synthesis in $0.15 \mathrm{MPy}+0.20 \mathrm{M}$ $\mathrm{K}_{2} \mathrm{HPO}_{4}$ aqueous solution. The potentials (V/SCE) at which the films were obtained are indicated. 
Table 3: Impedance models used for modelling the EIS responses of the OPPy films synthesized in one-step and the PPy films, as prepared and subsequently overoxidized in KOH solution. The equivalent electrical circuits are shown in Fig. 5 in which $Z_{W}$ is defined as $R_{u} /(j \omega)^{\beta}$.

\begin{tabular}{|c|c|c|}
\hline One-step OPPy film & PPy film as prepared & PPy film after overoxidation \\
\hline$Z_{\mathrm{t}}=R_{\mathrm{t}}+Z_{\text {Diff }}$ & $Z_{\mathrm{t}}=\frac{R_{\mathrm{t}}}{1+\left(\mathrm{j} \omega R_{\mathrm{t}} C_{\mathrm{dl}}\right)^{\alpha}}$ & $\frac{1}{Z_{\mathrm{t}}}=\mathrm{j} \omega C_{\mathrm{dl}}+\frac{1}{R_{\mathrm{t}}+R_{\mathrm{w}} /(\mathrm{j} \omega)^{\beta}}$ \\
\hline$Y=\frac{1}{Z_{\text {Young }}}+\frac{1}{Z_{\mathrm{t}}}$ & $\frac{1}{\mathrm{Z}_{\mathrm{f}}}=\mathrm{j} \omega \mathrm{C}_{\mathrm{f}}+\frac{(\mathrm{j} \omega)^{\beta}}{\mathrm{R}_{\mathrm{w}}}$ & $\frac{1}{Z_{\mathrm{f}}}=\mathrm{j} \omega C_{\mathrm{f}}+\frac{1}{R_{\mathrm{f}}}$ \\
\hline $\mathrm{Z}=R_{\mathrm{S}}+\frac{1}{Y}$ & $\mathrm{Z}=\mathrm{R}_{\mathrm{S}}+\mathrm{Z}_{\mathrm{t}}+\mathrm{Z}_{\mathrm{f}}$ & $Z=R_{\mathrm{S}}+Z_{\mathrm{t}}+Z_{\mathrm{f}}$ \\
\hline
\end{tabular}

However better simulations of the experimental data were obtained by considering two capacitive contributions in series according to the equivalent circuit reported in Figure 5(2) and Table 3 column 2, and discussed in the following. The Warburg coefficient was $R_{\mathrm{W}}=312$ $\Omega \mathrm{s}^{-0.5}$, similar to the value found for a bare platinum electrode. $R_{\mathrm{W}}$ is given by the following expression written for equimolar oxidized and reduced species at concentration $\mathrm{C}_{0}$ :

$$
R_{W}=\frac{2 \mathrm{RT}}{\mathrm{n}^{2} F^{2} \mathrm{C}_{0} \mathrm{~S}_{\mathrm{W}} \sqrt{\mathrm{D}}}
$$

where $F$ stands for the Faraday constant $(\mathrm{RT} / F=0.0258 \mathrm{~V}), \mathrm{n}$ the number of electrons exchanged ( $n=1$ herein), $S_{W}$ the surface concerned by the redox reaction and $D$ the mean diffusion coefficient for both redox species taken as $\mathrm{D}=7.10^{-6} \mathrm{~cm}^{2} \mathrm{~s}^{-1}$.[31] The measured value of $R_{\mathrm{W}}$ corresponds to an electrode surface of $0.065 \mathrm{~cm}^{2}$, in good agreement with the geometrical electrode surface $\left(0.071 \mathrm{~cm}^{2}\right)$. The apparent transfer rate constant, $\mathrm{k}_{0}$, can be calculated according to the expression: 


$$
k_{0}=\frac{R T}{n F^{2} C_{0} S_{W} R_{t}}
$$

$\mathrm{k}_{0}=0.15 \pm 0.02 \mathrm{~cm} \mathrm{~s}^{-1}$ is deduced from the transfer resistance $R_{\mathrm{t}}(\mathrm{PPy})=3.7 \pm 0.5$ $\Omega\left(0.26 \Omega \mathrm{cm}^{2}\right)$.

Therefore, the conductive surface fraction $\theta$ of the overoxidized OPPy films can be evaluated by comparing the values of the charge transfer resistance of the OPPy films $\left(R_{\mathrm{t}}\right.$, Table 2$)$ to that of the conductive PPy film. $\theta$ can be calculated as shown in Equation 10.

$$
\theta(\%)=100 \frac{R_{\mathrm{t}}(\mathrm{PPy})}{R_{\mathrm{t}}(\mathrm{OPPy})}
$$

$\theta$ values determined using this equation are listed in Table 2 . It can be seen that $\theta$ represents less than $0.001 \%$ of the electrode surface.

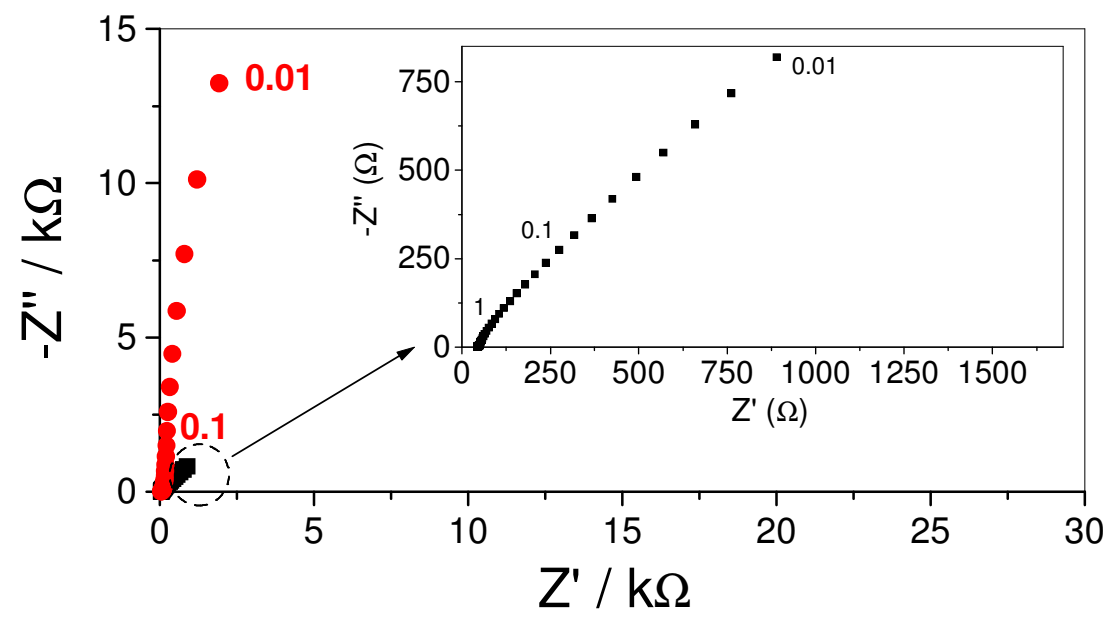

Figure 7: EIS response of a PPy-coated electrode. Nyquist EIS diagrams of a PPy-coated Pt electrode in contact with a $10 \mathrm{mM} \mathrm{Fe}(\mathrm{CN})_{6}^{4-3-}+0.5 \mathrm{M} \mathrm{KCl}$ solution recorded at $0.21 \mathrm{~V} / \mathrm{SCE}$. The PPy film was synthesized in a 0.2M $\mathrm{LiClO}_{4}+0.15 \mathrm{M}$ Py solution at $0.6 \mathrm{~V} / \mathrm{SCE}$; anodic charge $5 \mathrm{mC}$; before (-) and after (๑) a supplementary oxidation step in $0.1 \mathrm{M} \mathrm{KOH}$ solution at $0.75 \mathrm{~V} / \mathrm{SCE}$ for 20 minutes. Frequencies in $\mathrm{Hz}$. 
Figure 8 shows the dependence of the dielectric film capacity $C_{f}$ upon the anodic charge passed during the film synthesis at different applied potentials. The film capacity is found to vary as the inverse of the electrical charge, confirming that the film thickness is proportional to the anodic charge (see insert Fig. 8).

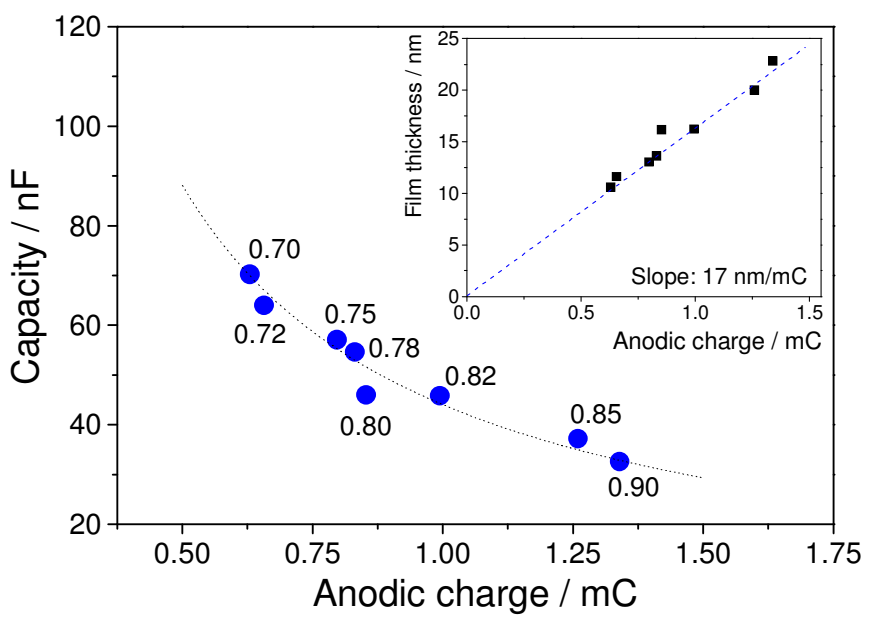

Figure 8: Capacity of OPPy films. Variation of the capacity of the OPPy films as a function of the electrical charge passed during their synthesis in $0.15 \mathrm{MPy}+0.20 \mathrm{M} \mathrm{K}_{2} \mathrm{HPO}_{4}$ aqueous solution. Insert: variation of the film thickness with the anodic charge. The potentials (V/SCE) at which the films were prepared are indicated.

3. OPPy film obtained by a two-step electrosynthesis process

As mentioned in the introduction, classically a blocking behaviour of a conducting PPy film is achieved via an additional oxidation step in $\mathrm{KOH}$ solution. Figures $3 \mathrm{~B}$ and 7 show the $\mathrm{CV}$ and EIS responses, respectively, of a doped PPy film in contact with the $\mathrm{Fe}(\mathrm{CN})_{6}{ }^{4-13-}$ solution. This film was synthesized in a $\mathrm{LiClO}_{4}$ solution at $+0.6 \mathrm{~V} / \mathrm{SCE}$ and was then further overoxidized at $0.75 \mathrm{~V} / \mathrm{SCE}$ in $0.1 \mathrm{M} \mathrm{KOH}$ solution. The anodic charge passed during the PPy film deposition was $5 \mathrm{mC}$ and its overoxidation treatment was performed for 20 or 40 minutes. 
For the doped PPy film, as already mentioned, the EIS impedance response can be modeled by assuming two contributions in series with the electrolyte resistance, the charge transfer impedance $Z_{t}$ and that of redox species transport inside the film $Z_{w}$ (see Figure 5(2) and Table 3). The charge transfer is represented by a parallel $\left(\mathrm{R}_{t}, \mathrm{C}_{\mathrm{dl}}\right)$ circuit assuming a Cole-Cole type distribution of time constants. The charge transport inside the film is represented by a generalized Warburg impedance $R_{\mathrm{w}} /(\mathrm{j} \omega)^{\beta}$ in parallel with the PPy film pseudo capacitance $\mathrm{C}_{\mathrm{f}}$. After overoxidation in $\mathrm{KOH}$ solution, the EIS scheme is modified: the Warburg impedance becomes in series with the transfer resistance $R_{\mathrm{t}}$, both in parallel with the double layer capacitance $C_{\mathrm{dl}}$; the film capacitance $C_{\mathrm{f}}$ lies in parallel with a resistance $R_{\mathrm{f}}$. Both models are detailed in Table 3 and the fitted parameters are gathered in Table 4. Taking into account the values of these parameters, two different pictures can be proposed for PPy films one before and one after overoxidation. For the as-prepared film, charge transfer takes place inside the porous film in the vicinity of the platinum substrate. Transport of redox species is represented by a generalized Warburg impedance in parallel with the large chemical film capacitance (around $400 \mu \mathrm{F}$ ). On the other hand, after an overoxidation step, charge transfer occurs close to the film/electrolyte interface: the transfer resistance, only increased by a factor 5-6, is in parallel with the double layer capacitance having a "standard" value $\left(40-50 \mu \mathrm{Fcm}^{-2}\right)$. But this external electroactive part of the film is connected to the platinum rear contact through a highly resistive material as pointed out by the very large value of the $R_{\mathrm{f}}$ resistance.

It has been noticed that after overoxidation, the color of the films slightly changes from grey to yellow, indicating that during the overoxidation treatment the polymeric film is partially dissolved. 
Table 4: EIS fitted parameters for a PPy film synthesized in pyrrole solution containing $\mathrm{LiClO}_{4}\left(Q_{\text {anodic }}=5 \mathrm{mC}\right)$ before and after an overoxidation step of 20 and 40 minutes according to the impedance models given in Table 3 (SD: standard deviation). Dashed boxes stand for non relevant parameters for the model used.

\begin{tabular}{|c|c|c|c|c|c|c|c|c|c|c|}
\hline $\begin{array}{l}\text { PPy } \\
\text { film }\end{array}$ & $\begin{array}{l}\mathrm{R}_{\mathrm{s}} \\
(\Omega)\end{array}$ & $\begin{array}{l}\mathrm{R}_{\mathrm{t}} \\
(\Omega)\end{array}$ & $\begin{array}{l}\mathrm{C}_{\mathrm{dl}} \\
(\mu \mathrm{F})\end{array}$ & $\alpha$ & $\begin{array}{c}\mathrm{C}_{\mathrm{f}} \\
(\mu \mathrm{F})\end{array}$ & $\begin{array}{c}\mathrm{R}_{\mathrm{w}} \\
\left(\Omega \mathrm{s}^{-\beta}\right)\end{array}$ & $\beta$ & $\begin{array}{l}\mathrm{R}_{\mathrm{f}} \\
(\Omega)\end{array}$ & SD & $\begin{array}{c}\text { Equiv. } \\
\text { electrical } \\
\text { circuit }\end{array}$ \\
\hline $\begin{array}{c}\text { As } \\
\text { prepared }\end{array}$ & 28.3 & 3.7 & 60 & 0.86 & 362 & 312 & 0.5 & & 1.031 & Fig. 5(2) \\
\hline $\begin{array}{l}\text { Overox. } \\
20 \mathrm{mn}\end{array}$ & 28.5 & 36 & 3.0 & & 306 & 252 & 0.352 & 131920 & 0.9898 & Fig. 5(3) \\
\hline $\begin{array}{l}\text { Overox. } \\
40 \mathrm{mn}\end{array}$ & 31.3 & 33 & 3.7 & & 421 & 258 & 0.384 & 28500 & 0.6907 & Fig. 5(3) \\
\hline
\end{tabular}

Finally, by comparing graphs A and C (same scale) in Figure 3 and the data in Tables 2 and 4, it can be concluded that the lowest electrochemical reactivity of the OPPy films is achieved by the one-step strategy. The OPPy films synthesized by this way are ultra thin and pine-hole free. Indeed the transfer resistance with respect to the ferri-ferrocyanide redox system is about ten thousand times higher using the one-step synthesis than using the two-step one, allowing to realize compact permselective ultra thin membranes.

\section{CONCLUSIONS}

In the presence of weak-acid anions in the pyrrole solution, strongly isolating overoxidized polypyrrole films were obtained and their blocking character is assessed by CV and EIS. The 
films formed at potentials between 0.7 and $0.9 \mathrm{~V} / \mathrm{SCE}$ in the presence of $\mathrm{HPO}_{4}{ }^{2-}$ anions in a one-step process behave as ultra thin $(15 \pm 5 \mathrm{~nm})$ and isolating membranes. Their impedance response is well accounted by using the Young model assuming uniform dielectric properties and a conductivity gradient perpendicular to the surface. By checking the electrochemical response to the ferri-ferrocyanide redox system, the remaining conductive part of the membrane was shown to be less than $0.001 \%$ of the geometric surface.

For comparison, conducting PPy films have been synthesized in the presence of perchlorate anions and subsequently electro-overoxidized in a $\mathrm{KOH}$ medium. For the as-prepared doped films, charge transfer is found to take place inside the porous film. On the other hand, after the overoxidation step, charge transfer occurs in the vicinity of the film/electrolyte interface, the electroactive interface being connected to the metal substrate via a highly resistive material. From the present studies, it can be concluded that for preparing ultra thin strongly isolating membranes the one-step strategy is more efficient in terms of a much lower electrochemical reactivity than that of requiring two steps. Thus, OPPy ultra thin membranes would constitute excellent candidates for electrochemical biosensors or for anticorrosion coatings.

\section{Acknowledgements}

The authors would like to thank Françoise Pillier for performing the SEM observations. 


\section{REFERENCES}

1. F. Beck, P. Braun, M. Oberst, Ber. Bunsen Phys. Chem. 91, 967 (1987)

2. F. Beck, U. Barsch, R. Michaelis, J. Electroanal. Chem. 351, 169 (1993).

3. H. L. Ge, G. J. Qi, E. T. Kang, K. G. Neoh, Polymer 35, 504 (1994).

4. F. Palmisano, C. Malitesta, D. Centonze, P. G. Zambonin, Anal. Chem 67, 2207 (1995).

5. A. Jaramillo, L. D. Spurlock, V. Young, A. Brajter-Toth, Analyst 124, 1215 (1999).

6. T. F. Otero, M. Marquez, I. J. Suarez, J. Phys. Chem. B 108, 15429 (2004).

7. M. Freund, L. Bodalbhai, A. Brajtertoth, Talanta 38, 95 (1991).

8. N. Hamdi, J. J. Wang, E. Walker, N. T. Maidment, H. G. Monbouquette, J. Electroanal. Chem. 591, 33 (2006).

9. C. Debiemme-Chouvy, Biosens. Bioelectron. 25, 2454 (2010).

10. C. Debiemme-Chouvy, M. Gallois, Surf. Interf. Anal. 42, 1144 (2010).

11. D. Centonze, A. Guerrieri, C. Malitesta, F. Palmisano, P. G. Zambonin, Fresen. J. Anal. Chem. 342, 729 (1992).

12. K. Pihel, Q. D. Walker, R. M. Wightman, Anal. Chem. 68, 2084 (1996).

13. B. R. P. Novak, W. Vielstich, J. Electrochem. Soc. 138, 3300 (1991).

14. M. J. Peairs, A. E. Ross, B. J. Venton, Anal. Methods 3, 2379 (2011).

15. N. Hamdi, J. J. Wang, H. G. Monbouquette, J. Electroanal. Chem. 581, 258 (2005).

16. L. Marchesi, F. R. Simoes, L. A. Pocrifka, E. C. Pereira, J. Phys. Chem. B 115, 9570 (2011).

17. A. Boateng, R. Cohen-Shohet, A. Brajter-Toth, Electrochim. Acta 56, 7651 (2011).

18. A. Boateng, F. Irague, A. Brajter-Toth, Electroanal. 25, 345 (2013).

19. C. Debiemme-Chouvy, T. T. M. Tran, Electrochem. Comm. 10, 947 (2008).

20. C. Debiemme-Chouvy, Electrochem. Solid State Lett. 10, E24 (2007). 
21. C. Debiemme-Chouvy, H. Cachet, C. Deslouis, Electrochim. Acta 51, 3622 (2006).

22. A. Lagrini, S. Charvet, M. Benlahsen, C. Debiemme-Chouvy, C. Deslouis, H. Cachet, Thin Solid Films 482, 41 (2005).

23. F. Alibart, O. D. Drouhin, C. Debiemme-Chouvy, M. Benlahsen, Solid State Comm. 145, 392 (2008).

24. J. A. Nelder, R. Mead, Comp. J. 7, 308 (1965).

25. L. Young, T. Faraday Soc. 51, 1250 (1955).

26. B. Tribollet, M. E. Orazem, Electrochemical Impedance Spectroscopy, Wiley, p 260, (2008).

27. C. A. Schiller, W. Strunz, Electrochim. Acta 46, 3619 (2001).

28. M. Salmon, K. K. Kanazawa, A. F. Diaz, M. Krounbi, J. Polym. Sci. Pol. Lett. 20, 187 (1982).

29. P. S. Abthagir, R. Saraswathi, J. Appl. Polym. Sci. 81, 2127 (2001).

30. J. Unsworth, A. Kaynak, B. A. Lunn, G. E. Beard, J. Mat. Sci. 28, 3307 (1993).

31. B. Robertson, B. Tribollet, C. Deslouis, J. Electrochem. Soc. 135, 2279 (1988). 